\title{
Mechanisms of reproductive suppression in female pine voles (Microtus pinetorum)
}

\author{
N. G. Solomon, C. L. Brant*, P. A. Callahan and B. A. Steinly, Jr \\ Department of Zoology, Miami University, Oxford OH 45056, USA
}

In co-operatively breeding birds and mammals, philopatric females are often reproductively suppressed. Many studies have focused on the functional significance of reproductive suppression, but further investigation of the mechanisms involved is required for a complete understanding of this process. This study investigated whether reproductive suppression in non-reproductive female pine voles (Microtus pinetorum) occurs as a result of lack of gamete maturation or lack of increase in LH. The behaviour of male pine voles was also examined to determine whether they show a preference for the mother versus her daughter, as lack of male stimulation may inhibit an increase of LH in daughter pine voles. Ovarian development and circulating
LH concentrations were investigated in females housed with a prospective mate in the presence or absence of a parent. Maturation of gametes was not affected by the presence of a parent. In the presence of the mother, there was no increase in $\mathrm{LH}$, as was observed in females housed with or exposed to a novel male. Males spent more time with mothers and possibly showed a preference for mating with the mother. These results are consistent with the contention that ovulation does not occur in female pine voles housed in the presence of their mother; however, it is not clear whether the lack of ovulation is caused by lack of stimulation from the male or suppression by the mother.

\section{Introduction}

Co-operative breeding, the care of young by individuals other than the parents (Emlen, 1982), has been recorded in more than 220 avian (Emlen, 1991) and 120 mammalian species (Riedman, 1982; Solomon and French, 1997). The formation of co-operatively breeding social groups occurs when offspring remain philopatric, that is, at the natal nest, and become alloparents or helpers (Brown, 1987; Jennions and Macdonald, 1994). Females that remain philopatric are often reproductively suppressed (Wasser and Barash, 1983; Emlen, 1991; Keller and Reeve, 1994). Determining the functional significance and mechanisms of reproductive suppression is critical to a complete understanding of co-operative breeding (Stamps, 1991). There are three alternative mechanisms concerning the stage at which reproductive suppression occurs.

The first alternative is that reproductive suppression occurs as a result of suppression of gamete development (Haigh, 1987). Reports of a delay in maturation of gametes in some social contexts, for example, in the presence of a female or a group of females (Frankiewicz and Marchlewska-koj, 1985; Kruczek and Marchlewska-koj, 1986), are examples of this mechanism. In these studies, females that were housed with another female had significantly fewer Graafian follicles than did those housed alone or with a male.

Email: solomong@muohio.edu

*Present address: 12493 Cedar Road \#12, Cleveland Heights, $\mathrm{OH}$ 44106, USA
The second explanation is that there is suppression of ovulation. In two species of mole-rat and in callitrichid monkeys, subordinate females have significantly lower concentrations of $\mathrm{LH}$ in the presence of a dominant female compared with subordinate females housed alone (Abbott, 1984; Savage et al., 1988; Faulkes et al., 1990a; Barrett et al., 1993; Bennett et al., 1993; Molteno and Bennett, 2000). In these species, reproductive suppression was due to events that occurred at the anterior pituitary, in which a decrease in the release of $\mathrm{LH}$ prevented ovulation.

The third possible explanation is that reabsorption of the embryo occurs in philopatric individuals. However, reabsorption of the embryo does not appear to be a common mechanism of reproductive suppression, although in some cases subordinate female wolves (Canis lupus) and dwarf mongooses (Helogale parvula) copulated but did not produce any pups (Rood, 1980; Packard et al., 1985).

Another factor that can be related to reproductive suppression in philopatric females is a lack of stimulation from a potential mate (Schoech et al., 1991, 1996). Lack of appropriate social stimulation may occur if an individual does not encounter a potential mate while remaining at its natal nest. On occasions, a breeder dies or disappears and is subsequently replaced. If a breeder is replaced, oppositesex offspring still may not breed if the replacement prefers to mate with the remaining breeder. No other study has focused on the behaviour of this individual, whose presence could affect reproduction of opposite-sex group members.

Other studies on the physiological mechanisms of reproductive suppression have focused on species that have 
spontaneous oestrous cycles (Abbott et al., 1981; Epple and Katz, 1984; Savage et al., 1988; French et al., 1989; Faulkes et al., 1990a; Creel et al., 1991, 1997), but little attention has been given to species that have induced oestrous cycles, such as arvicoline rodents (voles and lemmings). Therefore, the purpose of the present study was to investigate the physiological mechanisms of reproductive suppression in female pine voles (Microtus pinetorum). In addition, the preference of males for mothers versus daughters was investigated. The pine vole lives in social groups that typically consist of one breeding female, one or more breeding males and non-breeding young, presumably from previous litters (FitzGerald and Madison, 1983; Marfori et al., 1997; Solomon et al., 1998). Under field conditions, only one female mated in $80-100 \%$ of groups (Solomon et al., 1998). In laboratory experiments, mature daughters housed with their mothers and an unrelated adult male produced significantly fewer litters compared with daughters housed only with an adult male (Schadler, 1990; Brant et al., 1998).

The reproductive physiology of female pine voles is similar to that of female prairie voles (M. ochrogaster), a congener in which more details of reproductive physiology are known. Pine voles, like many other arvicoline rodents, are induced into oestrus by the presence of an unfamiliar conspecific male (Richmond and Stehn, 1976; Schadler and Butterstein, 1979; Solomon et al., 1996). LH and oestrogen concentrations are low before interaction with an unfamiliar male (Richmond and Stehn, 1976; Carter et al., 1980, 1989; Schadler and Butterstein, 1987). Circulating concentrations of $\mathrm{LH}$ are regulated by a negative feedback mechanism similar to that of females with spontaneous oestrous cycles (Moffatt et al., 1995). In prairie voles, GnRH, released from the olfactory bulb, stimulates $\mathrm{LH}$, and probably $\mathrm{FSH}$, secretion from the anterior pituitary lobe (Dluzen et al., 1981). Gonadotrophin secretion results in follicular development and subsequent production of oestrogen.

\section{Materials and Methods}

\section{Animals and treatment}

The pine voles used in these experiments were descendants of animals trapped in the wild in Henderson County, North Carolina. All animals were treated in accordance with standards described in the NIH Guide for the Care and Use of Laboratory Animals (1985). Experimental animals were obtained by setting up breeding pairs in $38 \mathrm{~cm} \times 33 \mathrm{~cm} \times 17 \mathrm{~cm}$ cages. Food (Purina Rodent Breeder Chow No. 5013) and water were provided ad libitum. Cages were provided with paper fibre (Carefresh; Fangman Industries, Cincinnati, $\mathrm{OH}$ ) as bedding and nesting material (Nestlets; Ancare Inc., North Billmore, NY). Experimental animals were housed with both parents and their siblings before the start of the experiment. Subsequent litters were removed from cages housing the family when pups reached 24-30 days of age so that there were not more than two litters of pups in each cage. At the start of the experiment, experimental animals were housed in an adjoining room. Corn cob bedding and Nestlets (Ancare Inc.) were used in all experimental cages. Both animal rooms were maintained on a $14 \mathrm{~h}$ light:10 h dark photoperiod, with lights switched on at 06:00 h. Room temperatures were maintained at $22 \pm 1^{\circ} \mathrm{C}$.

\section{Experiment 1}

Housing conditions. Unlike studies of naked mole-rats (Heterocephalus glaber) and callitrichid monkeys in which ovarian cyclicity was examined in the absence of a conspecific male, the presence of a potential mate was necessary to induce oestrus in pine voles (Brant et al., 1998). Daughters were removed from their family groups at 75-85 days of age and were paired with an unfamiliar unrelated mature male that was 65-110 days of age. These age ranges were selected because male and female pine voles reach puberty at 57-60 and 60-77 days of age, respectively (Schadler and Butterstein, 1979; Lepri and Vandenbergh, 1986). Pairs of pine voles were assigned randomly to one of three treatment groups. In the first treatment group, the mother was housed with the male-daughter pair to determine the effects of the presence of the mother on gamete maturation. The second treatment group was male-daughter pairs with the father and served as a control for the presence of another individual in the group. In the third treatment group, a male-daughter pair was housed in the absence of a parent and served as a positive control. Animals were housed in $38 \mathrm{~cm} \times 33$ $\mathrm{cm} \times 17 \mathrm{~cm}$ cages. All treatments continued until a litter was produced or for 60 days, a time span greater than two periods of gestation (Schadler and Butterstein, 1979). More than $60 \%$ of daughters housed with their mother and an unfamiliar male did not produce litters (Brant et al., 1998). The presence of the father had little effect on reproduction: only $31 \%$ of daughters did not produce offspring compared with $21 \%$ of male-daughter pairs.

Daughters that had not given birth within 60 days were considered as 'non-reproducing females' and some of these animals were killed by administration of an overdose of sodium pentobarbital (mother present, $n=8$; father present, $n=5$; and neither parent present, $n=4)$. In addition, females that produced a litter $(n=4)$ were killed 2 days after their first litter was born. The latter provided data on gamete maturation in reproductively active females. The ovaries and uteri from daughters were excised, cleaned of connective tissue and weighed to the nearest $0.1 \mathrm{mg}$. Uteri were examined under a dissecting microscope for uterine scars, indicating implantation of embryos. Sections from ovaries were examined for follicular development and the presence of corpora lutea, the latter indicating that ovulation had occurred.

Histological methods. Ovaries were placed in Bouin's fixative for $48 \mathrm{~h}$. The fixative was removed and replaced 
with $70 \%(\mathrm{v} / \mathrm{v})$ ethanol. The alcohol was replaced each day until all excess picric acid was removed. When necessary, ovaries were washed twice in $\mathrm{Li}_{2} \mathrm{CO}_{3}$ saturated in $70 \%$ $(\mathrm{v} / \mathrm{v})$ ethanol to facilitate removal of picrates.

Ovaries were dehydrated in a series of alcohol washes (80-100\% (v/v) ethanol). After the final wash, methyl benzoate and then methyl benzoate-1\% (v/v) celluloiden solution were added to each sample. After $12 \mathrm{~h}$, the methyl benzoate-1\% ( $/ \mathrm{v} / \mathrm{v})$ celluloiden solution was removed and replaced with toluene. The tissue was embedded in Paraplast and sectioned using a rotary microtome set at $8 \mu \mathrm{m}$. Sections were placed on slides coated with a $34 \%$ $(\mathrm{v} / \mathrm{v})$ albumin solution, stained with haematoxylin and counterstained with eosin (Humason, 1962). All sections from both ovaries of each female were examined. For each female, the most advanced follicular stage was recorded.

\section{Experiment 2}

$\mathrm{LH}$ concentrations were determined in mature sexually inexperienced female pine voles that were either housed alone or exposed to an unfamiliar adult male separated by a wire mesh barrier. Schadler and Butterstein (1987) demonstrated that the presence of a male separated by a permeable mesh barrier resulted in a significant increase in the concentration of $\mathrm{LH}$ in mature sexually inexperienced female pine voles compared with females that were not exposed to a male. Mature female pine voles $(n=12)$ were removed from their families at 75-85 days of age. Eight of these animals were housed so that they were exposed to a mature (65-110 days of age) sexually inexperienced, unfamiliar, unrelated male separated by a single wire mesh barrier $(38 \mathrm{~cm} \times 33 \mathrm{~cm} \times 17 \mathrm{~cm}$ cage divided in half lengthwise by a mesh barrier). The other four females were housed individually in separate cages. All trials started in the morning and lasted 7 days. On day 8, daughters were lightly anaesthetized with $2 \mathrm{ml}$ Metophane (Pitman-Moore Inc., Madelein, IL) and killed by decapitation. Trunk blood was collected in Eppendorf tubes containing two drops of heparin $\left(1000 \mathrm{U} \mathrm{ml}^{-1}\right)$. Samples of blood were centrifuged (3000 $\mathbf{g}$ for $15 \mathrm{~min}$ ), and the plasma was collected and stored at $-20^{\circ} \mathrm{C}$ until radioimmunoassay.

In a second experiment, LH concentrations were determined under three different housing conditions. Mature sexually inexperienced daughters (75-85 days of age) were removed from family groups as described and subjected to one of the following treatments for 7 days: (i) daughter isolated ( $n=12)$; (ii) daughter housed with her mother and separated by a single wire mesh barrier from an unfamiliar unrelated mature male $(n=7)$; and (iii) daughter separated by a single wire mesh barrier from a unfamiliar unrelated mature male $(n=8)$. On day 8 , plasma was collected and stored as described for Experiment 1.

Determination of hormone concentrations. LH concentrations were measured in duplicate samples by double antibody radioimmunoassay using kits provided by the National Hormone and Pituitary Program (NHPP), the National Institute of Diabetes and Digestive and Kidney Diseases (NIDDK) and by A. F. Parlow. Rat LH reagents were used in these experiments because reagents specific for vole LH are not available. Schadler and Butterstein (1987) found that rat $\mathrm{LH}$ radioimmunoassay reagents showed good crossreactivity to pine vole LH and that serum dilution curves were parallel to the standard curves. A competition standard curve was constructed using excess rat $\mathrm{FSH}\left(5 \mathrm{ng} \mathrm{ml}^{-1}\right)$ to verify the specificity of the primary antibody. The presence of excess FSH did not displace $\mathrm{LH}$ binding, indicating that there was no crossreactivity with FSH.

Plasma LH was expressed as ng equivalents of the reference LH (rLH-RP3). Primary antibody (anti-rLH-S-11) was specific for the beta subunit of $\mathrm{LH}$. The radiolabelled hormone (125/-labelled rat-LH) was obtained from Covance Laboratories (Vienna, West Virginia) and goat anti-rabbit gamma globulin (second antibody) was obtained from Antibodies, Inc. (Davis, CA). The intra-assay coefficient of variation was $<5 \%$ and the lowest limit of detection was $0.3325 \mathrm{ng} \mathrm{ml}^{-1}$.

\section{Experiment 3}

Daughters remained in their family cages, as described in Expt 1, with their parents and any siblings that may have been present until they reached 75-85 days of age. At that time, the daughter and her mother were fitted with cable tie collars and subsequently returned to their family cage overnight to habituate to the collars. These collars have been used in other experiments on voles (Solomon, 1993) and it has been shown that animals adapt to them relatively quickly. The next day, both females were removed from the family cage and tethered by their collars to the choice apparatus to prevent interactions between them. The side of the chamber on which each type of female (mother or daughter) was located, was alternated to avoid position effects (preference for either the right or left chamber irrespective of odour source).

The choice apparatus consisted of a clear Plexiglas cage $(61 \mathrm{~cm} \times 22 \mathrm{~cm} \times 20 \mathrm{~cm})$ that had a screen-wire lid. The apparatus was divided into three equal sized chambers, separated by removable Plexiglas partitions. Each partition had a hole of $2.2 \mathrm{~cm}$ in diameter allowing the test subject access to all chambers. Each female could move freely within her chamber, but could not move into another chamber.

The entire choice apparatus contained bedding and each chamber had a Nestlet for nest construction. Food and water were provided ad libitum in each end chamber. After each trial, the choice apparatus was cleaned with unscented detergent (Quatricide 20; Pharmacal Research Labs, Naugatuck, CT) and water to remove urine and odours.

Sexually inexperienced adult males, which were at least 85 days of age and had been housed with siblings for at least 
1 week before the experiment, were used as test subjects $(n=16)$. Males were unfamiliar with the mother and daughter. The male was gently introduced into the centre chamber and was given simultaneous access to both females. The behaviour of all three individuals was recorded with a time-lapse video for 5 days. Two red lights $(25 \mathrm{~W})$ were used to illuminate the test apparatus during the dark phase of the cycle so that filming could continue uninterrupted. Tapes were viewed and the amount of time the male spent with the mother and daughter was quantified. As tapes were viewed at one sixth of the recorded speed, this factor was used to convert the time spent in each end chamber into real time. In addition, the females that the males nested and mated with were recorded as additional measures of preference.

\section{Statistical analyses}

A one-way ANOVA was used to determine the significant differences between body weight and organ mass for daughters that did not produce offspring within 60 days of pairing with a male. The Student's $t$ test was used to determine whether the presence of an unfamiliar male across a barrier resulted in a significant increase in $\mathrm{LH}$. ANOVA was also used to determine the effects of different housing conditions, that is, pairs housed alone compared with pairs housed with either the mother or the father, on LH concentrations. When significant $F$ values were obtained, Fisher's least significant difference post hoc tests were performed. Plasma concentrations of $\mathrm{LH}$ from three animals were below the limit of detection and, therefore, were excluded from analysis. Two of these samples were collected from isolated daughters and one sample was collected from a daughter housed in the presence of her mother.

In Expt 3, the possibility of position effects (preference for either the right or left chamber irrespective of stimulus animal) was examined using a binomial test. Preference for nesting with the mother was examined using a binomial test. Time spent with each stimulus animal was analysed using a paired $t$ test. All data are expressed as mean \pm SE and $P<0.05$ was considered significant.

\section{Results}

There were no significant differences among treatments in body weights $\left(F_{2,14}=0.613, P=0.556\right)$ or ovarian masses $\left(F_{2,14}=0.353, P=0.708\right)$ of daughters that did not produce litters, regardless of housing condition (Table 1). However, uterine masses were significantly different among treatments $\left(F_{2,14}=4.634, P=0.029\right)$. Uteri of daughters housed in the presence of their mothers weighed much less than those of daughters housed in the absence of a parent. Daughters housed in the presence of their father had intermediate uterine masses. There was no difference in gamete maturation among treatments. Secondary or Graafian follicles were present in the ovaries of daughters that did not produce litters, but implantation scars were not observed. Graafian
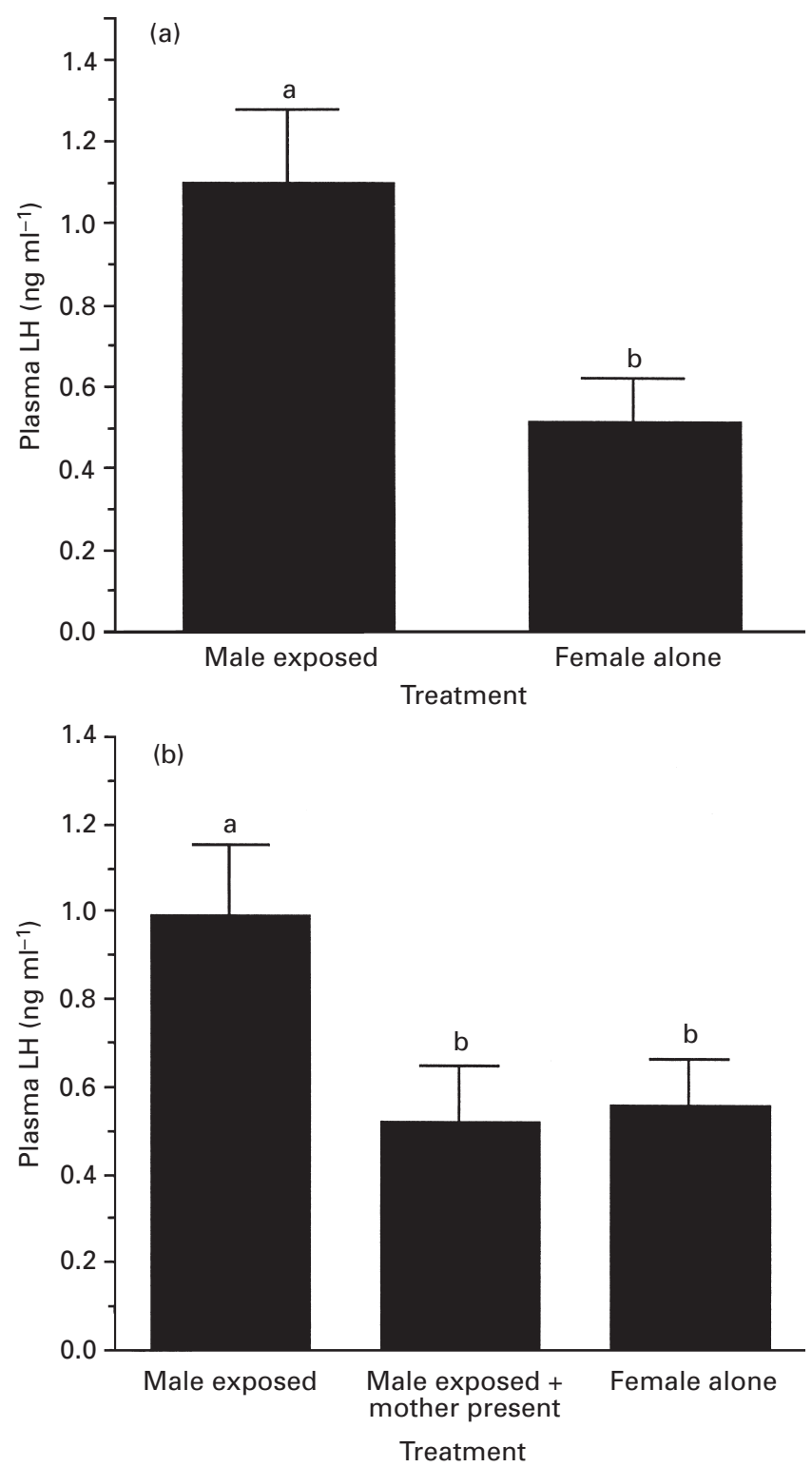

Fig. 1. (a) Plasma $\mathrm{LH}$ concentrations expressed as $\mathrm{ng} \mathrm{ml}^{-1}$ (mean $\pm \mathrm{SE}$ ) for daughters with or without male exposure (female alone) and (b) LH concentrations for daughters with either male exposure, male exposure in the presence of their mother or no male exposure (female alone) in the pine vole (Microtus pinetorum). ${ }^{a b}$ Different letters indicate a significant difference among treatments $(P<0.05)$.

follicles were observed in $75 \%$ of daughters housed with their mother compared with $100 \%$ of daughters housed with their father and $100 \%$ housed with only an unfamiliar male. Gamete development in daughters that did not produce litters was similar to that of females that did produce litters ( $75 \%$ had Graafian follicles) except that corpora lutea were also present in the ovaries of females that produced litters.

LH concentrations in daughters exposed to males across a wire mesh barrier were significantly higher than those 
Table 1. Mean ( $\pm \mathrm{SE}$ ) body weights, and ovarian and uterine masses of pine voles (Microtus pinetorum) for daughters that did not produce pups

\begin{tabular}{lccc}
\hline & $\begin{array}{c}\text { Mother present } \\
(n=8)\end{array}$ & $\begin{array}{c}\text { Father present } \\
(n=5)\end{array}$ & $\begin{array}{c}\text { Neither parent present } \\
(n=4)\end{array}$ \\
\hline Body weight $(\mathrm{g})$ & $21.8 \pm 1.3$ & $24.6 \pm 2.0$ & $23.7 \pm 3.0$ \\
Ovarian mass $(\mathrm{mg})$ & $7.5 \pm 4.3$ & $4.7 \pm 1.1$ & $3.3 \pm 0.8$ \\
Uterine mass $(\mathrm{mg})$ & $11.2 \pm 2.1$ & $22.5 \pm 9.0$ & $32.5 \pm 2.4^{*}$ \\
\hline
\end{tabular}

*Significantly different compared with group in which mother was present $(P<0.05)$.

of isolated females $\left(t_{10}\right)=2.199, P=0.052$; Fig. 1a). Furthermore, females exposed to a male separated by a wire mesh partition had significantly higher LH concentrations compared with females that were exposed to a male in the presence of their mother or in isolated females $\left(F_{2,21}=3.80\right.$, $P=0.039$; Fig. 1b). There was no significant difference between LH concentrations in daughters exposed to males in the presence of their mother or in isolated daughters.

Male pine voles spent significantly more time with the mother $(75.2 \pm 7.0 \mathrm{~h})$ than with the daughter $(36.3 \pm 7.1 \mathrm{~h}$; $t=2.87, P=0.012, n=16$ ), but did not display a preference for the right or left chambers (two-tailed binomial test, $P=$ 0.804). At the end of the 5 day test period, $81 \%$ of males were found in the chamber with the mother (one-tailed binomial test, $P=0.011)$. Of the males that built nests $(71.4 \%)$ with one of the females, there was a tendency to build nests in the chamber with the mother but the effect was not significant (one-tailed binomial test). Three males did not mate with either female during the 5 day test period. Of the males that mated, 6 of $13(46.0 \%)$ mated only with the mother, although 5 of 13 (38.5\%) mated with both the mother and daughter. The remaining two males (15.4\%) mated only with the daughter.

\section{Discussion}

The results of the present study are consistent with the proposed mechanism that mating and, therefore, ovulation in daughters do not occur in the presence of the mother even when a potential mate is present. LH concentrations were significantly lower in daughters paired with unfamiliar unrelated males in the presence of the mother than in the absence of the mother. Indeed, LH concentrations of daughters exposed to males in the presence of their mother were as low as those observed in isolated daughters. These data indicate that the release of $\mathrm{LH}$ was suppressed in daughters exposed to males in the presence of their mother. Some stages of the mechanism involved in reproductive suppression may be similar in species in which there are differences between $\mathrm{LH}$ concentrations of breeders and non-breeders. Subordinate, non-breeding female naked mole-rats, Damaraland mole-rats (Cryptomys damarensis) and callitrichid monkeys also show low concentrations of LH compared with dominant breeding females (Savage et al., 1988; Barrett et al., 1990, 1993; Faulkes et al., 1990a;
Bennett et al., 1993, 1996; Snowdon et al., 1993). However, differences in LH concentrations between breeding and non-breeding females are not found in all cooperatively breeding mammals. LH concentrations of nonbreeding female Mashona mole-rats (C. darlingi), giant mole-rats $(C$. mechowi) and common mole-rats $(C$. hottentotus) are not significantly different from those of breeding females (Bennett et al., 1997, 2000; Bennett and Faulkes, 2000). In giant mole-rats and common mole-rats, reproduction may be inhibited by inbreeding avoidance within intact colonies. Although inbreeding avoidance is also likely to prevent breeding in intact families of pine voles, the lack of reproduction in the presence of an unfamiliar male and the mother is more consistent with a physiological block to reproduction as shown by decreased concentrations of $\mathrm{LH}$.

Consistent with the lack of an LH increase in daughters housed with their mothers, there was also no uterine hypertrophy in daughters housed under similar conditions. Contact with an unfamiliar adult male induces secretion of $\mathrm{LH}$ and oestrogen, the latter causing cell proliferation in the uterus (Hasler and Conway, 1973). Cell proliferation is often detected by an increase in uterine mass. This measure has often been used as an indirect method for determining whether oestrogen secretion has occurred (Lepri and Vandenbergh, 1986; Solomon et al., 1996). Thus, the significantly lower uterine masses of daughters housed with their mothers indicate that these females do not have the same physiological responses as females housed with only an unfamiliar male.

Male preference may be a factor that contributed to the lack of reproduction in daughters. Males showed a preference for the mother rather than her daughter in terms of the time spent with the mother and, to some extent, in nesting with the mother. Preference, as defined by actual mating, was more difficult to interpret. Approximately half of the males mated exclusively with the mother and most of the remaining males mated with both females. Thus, it appears that the male may have a preference for the mother.

In addition, as males spent more time with the mother, the lower level of stimulation by the male may have contributed to the lack of increase in oestrogen and $\mathrm{LH}$ in daughters. Low concentrations of these hormones would not be sufficient to induce behavioural oestrus and, thus, daughters would not be willing to mate. The same pattern of 
behaviour was also observed in a study by Brant et al. (1998), in which males spent less time in contact with daughters, and sniffed the anogenital region and mounted daughters less frequently in the presence of the mother. Thus, although the term 'suppression' has been used, the lack of mating could be due to a lack of male stimulation. Alternatively, this pattern of behaviour may be due to a decrease in attractiveness of the daughter (Beach, 1976), which would be consistent with lower concentrations of oestrogen and $\mathrm{LH}$. The results of the present study do not allow the direction of causality to be determined.

As FSH did not compete with $\mathrm{LH}$ in the radioimmunoassay, it is likely that the results from the present study reflect a suppression of LH concentrations only and are not due to suppression in $\mathrm{FSH}$. Histological examination of ovaries confirmed that FSH was not suppressed as follicular development was occurring. Results from the present study showed that daughters that did not reproduce after being paired with a male in the presence of their mother had mature ovarian follicles. As FSH is necessary for maturation of follicles (Nelson, 1995), it is likely that LH, but not FSH, was suppressed.

Although the ovaries from immature females were not examined in the present study, Schadler (1977) reported that in 8-week-old females, ovarian follicles are less mature than those of mature females and mothers. In immature females, a large number of secondary follicles were observed, but Graafian follicles were rarely observed. In contrast, mature females had abundant Graafian follicles. Willingstorfer et al. (1998) suggested that lack of reproduction in female Zambian mole-rats (Cryptomys sp.) is not due to lack of maturation of ovarian follicles as there were no differences in the sizes of the ovaries or in the number of follicles in breeding and non-breeding females. Furthermore, in pine voles, lack of litter production did not result from reabsorption of embryos since none of the daughters had uterine scars. Therefore, these results do not support mechanisms proposing suppression of gamete development or reabsorption of embryos.

The results of the present study provide an initial step in determining the physiological mechanisms involved in lack of reproduction in female pine voles (daughters). Behavioural interactions with the mother (Brant et al., 1998) and the male appear to play an important role in the lack of reproduction in daughters indicating that higher brain input to the hypothalamus may be important in reproductive suppression in this, as in other, species. For example, when subordinate female Mashona mole-rats were treated with $\mathrm{GnRH}$, they showed an increased secretion of $\mathrm{LH}$ from the anterior pituitary gland, which was similar in magnitude to that of reproductive females (Bennett et al., 1997). This responsiveness to the exogenous administration of $\mathrm{GnRH}$ indicates that the anterior pituitary gland is not desensitized to stimulation, but that endogenous GnRH secretion is decreased. This study also indicates that reproductive suppression in Mashona mole-rats occurs at the hypothalamus, preventing the release of gonadotrophins from the anterior pituitary. In contrast, when GnRH was administered to reproductive and non-reproductive female common marmosets (Callithrix jacchus) and Damaraland mole-rats, there were smaller increases in the LH concentrations of non-reproductive females compared with reproductive females (Abbott et al., 1988; Bennett et al., 1993). This same pattern was observed when low doses of GnRH were administered to breeding and non-breeding female naked mole-rats (Faulkes et al., 1990b). The results from the study by Faulkes et al. (1990b) indicate that the anterior pituitary gland of non-reproductive, subordinate females is not as sensitive to $\mathrm{GnRH}$ administration as that of reproductive females. Therefore, there may be a difference in the level at which suppression occurs in the first and the latter three species. In subordinate female Mashona molerats, suppression appears to occur at the hypothalamus, whereas in subordinate female Damaraland mole-rats and common marmosets, suppression seems to occur at the anterior pituitary gland. However additional studies, including generating full dose-response curves using a range of $\mathrm{GnRH}$ doses, are required to determine the responsiveness of the pituitary to $\mathrm{GnRH}$ stimulation. Further studies are required to determine whether the anterior pituitary gland is desensitized to stimulation, that is, 'suppressed', in female pine voles or whether suppression occurs at the hypothalamus as seems to occur in Mashona mole-rats.

The authors thank S. Klosterman and K. Zechiel Peters for assistance with the radioimmunoassay, B. Schaefer for advice on statistical analyses and F. Baerveldt who assisted with histological preparation of ovaries. The authors greatly appreciate the help of numerous students, including C. Ball, F. Baerveldt, A. Torok, R. O'Boyle, T. Feinstein, J. Harhay, T. Rumbaugh, H. Main, M. Sorice, E. Hirsch and K. Paladino, for help with Expt 3. The authors also thank two anonymous reviewers for their thoughtful comments on a previous version of this manuscript. This study was supported by a grant from the National Institute of Health (NIH MH 52471-01) to N. G. Solomon.

\section{References}

Abbott DH (1984) Behavioral and physiological suppression of fertility in subordinate marmoset monkeys American Journal of Primatology 6 169-186

Abbott DH, McNeilly AS, Lunn SF, Hulme MJ and Burden FJ (1981) Inhibition of ovarian function in subordinate female marmoset monkeys (Callithrix jacchus jacchus) Journal of Reproduction and Fertility 63 335-345

Abbott DH, Hodges JK and George LM (1988) Social status controls LH secretion and ovulation in female marmoset monkeys (Callithrix jacchus) Journal of Endocrinology 117 329-339

Barrett J, Abbott DH and George LM (1990) Extension of reproductive suppression by pheromonal cues in subordinate female marmoset monkeys, Callithrix jacchus. Journal of Reproduction and Fertility 90 $411-418$

Barrett J, Abbott DH and George LM (1993) Sensory cues and the suppression of reproduction in subordinate female marmoset monkeys, Callithrix jacchus. Journal of Reproduction and Fertility 97 301-310

Beach FA (1976) Sexual attractivity, proceptivity and receptivity in female mammals Hormones and Behavior 7 105-138 
Bennett NC and Faulkes CG (2000) African Mole-rats: Ecology and Eusociality Cambridge University Press, Cambridge

Bennett NC, Jarvis JUM, Faulkes CG and Millar RP (1993) LH responses to single doses of exogenous GnRH by freshly captured Damaraland molerats, Cryptomys damarensis. Journal of Reproduction and Fertility $\mathbf{9 9}$ $81-86$

Bennett NC, Faulkes CG and Molteno AJ (1996) Reproductive suppression in subordinate, non-breeding female Damaraland mole-rats: two components to a lifetime of socially induced infertility Proceedings of the Royal Society of London B 263 1599-1603

Bennett NC, Faulkes CG and Spinks AC (1997) LH responses to single doses of exogenous $\mathrm{GnRH}$ by social Mashona mole-rats: a continuum of socially induced infertility in the family Bathyergidae Proceedings of the Royal Society of London B 264 1001-1006

Bennett NC, Molteno AJ and Spinks AC (2000) Pituitary sensitivity to exogenous GnRH in giant Zambian mole-rats, Cryptomys mechowi (Rodentia: Bathyergidae): support for the 'socially induced infertility continuum' Journal of Zoology, London 252 447-452

Brant CL, Schwab TM, Vandenbergh JG, Schaefer RL and Solomon NG (1998) Behavioral suppression of female pine voles after replacement of the breeding male Animal Behaviour 55 615-627

Brown JL (1987) Helping and Communal Breeding in Birds Princeton University Press, Princeton

Carter CS, Getz LL, Gavish L, McDermott JL and Arnold P (1980) Malerelated pheromones and the activation of female reproduction in the prairie vole (Microtus ochrogaster) Biology of Reproduction 23 1038-1045

Carter CS, Witt DM, Manock SR, Adams KA, Bahr JM and Carlstead K (1989) Hormonal correlates of sexual behavior and ovulation in maleinduced and postpartum estrus in female prairie voles Physiology and Behavior 46 941-948

Creel S, Creel N, Wildt DE and Monfort SL (1991) Behavioral and endocrine mechanisms of reproductive suppression in Serengeti dwarf mongooses Animal Behaviour 43 231-245

Creel S, Creel NM, Mills MGL and Monfort SL (1997) Rank and reproduction in cooperatively breeding African wild dogs: behavioral and endocrine correlates Behavioral Ecology 8 298-306

Dluzen DE, Ramirez VD, Carter CS and Getz LL (1981) Male vole urine changes luteinizing hormone-releasing hormone and norepinephrine in female olfactory bulb Science 212 573-575

Emlen ST (1982) The evolution of helping-I: an ecological constraints model American Naturalist 119 29-39

Emlen ST (1991) Evolution of cooperative breeding in birds and mammals. In Behavioral Ecology: an Evolutionary Approach pp 301-337 Eds JR Krebs and NB Davies. Blackwell Scientific Publications, Oxford

Epple G and Katz Y (1984) Social influences on estrogen excretion and ovarian cyclicity in saddle back tamarins (Sanguinus fusicollis) American Journal of Primatology 6 215-227

Faulkes CG, Abbott DH and Jarvis JUM (1990a) Social suppression of ovarian cyclicity in captive and wild colonies of naked mole-rats, Heterocephalus glaber. Journal of Reproduction and Fertility 88 559-568

Faulkes CG, Abbott DH, Jarvis JUM and Sherriff FE (1990b) LH responses of female naked mole-rats, Heterocephalus glaber, to single and multiple doses of exogenous GnRH Journal of Reproduction and Fertility $89317-323$

FitzGerald RW and Madison DM (1983) Social organization of a freeranging population of pine voles, Microtus pinetorum. Behavioral Ecology and Sociobiology 13 183-187

Frankiewicz J and Marchlewska-koj A (1985) Effect of conspecifics on sexual maturation in female European pine voles (Pitymys subterraneus) Journal of Reproduction and Fertility 74 153-156

French JA, Inglett BJ and Dethlefs TM (1989) The reproductive status of nonbreeding group members in captive golden lion tamarin social groups American Journal of Primatology 18 73-86

Haigh GR (1987) Reproductive inhibition of female Peromyscus leucopus: female competition and behavioral regulation American Zoologist 27 867-878

Hasler MJ and Conway CH (1973) The effect of males on the reproductive state of female Microtus ochrogaster. Biology of Reproduction 9 426-436
Humason GL (1962) Animal Tissue Techniques WH Freeman and Co., San Francisco

Jennions MD and Macdonald DW (1994) Cooperative breeding in mammals Trends in Ecology and Evolution 9 89-93

Keller L and Reeve HK (1994) Partitioning of reproduction in animal societies Trends in Ecology and Evolution 9 98-102

Kruczek M and Marchlewska-koj A (1986) Puberty delay of bank vole females in a high-density population Biology of Reproduction 35 $537-541$

Lepri JJ and Vandenbergh JG (1986) Puberty in pine voles, Microtus pinetorum, and the influence of chemosignals on female reproduction Biology of Reproduction 34 370-377

Marfori MA, Parker PG, Gregg TG, Vandenbergh JG and Solomon NG (1997) Using DNA fingerprinting to estimate relatedness within social groups of pine voles Journal of Mammalogy 78 715-724

Moffatt CA, Gerber JM, Blom JM, Kriegsfeld LJ and Nelson RJ (1995) Photoperiodic effects on steroid negative feedback in female prairie voles (Microtus ochrogaster) General and Comparative Endocrinology 100 92-95

Molteno AJ and Bennett NC (2000) Anovulation in non-reproductive female Damaraland mole-rats (Crypotmys damarensis) Journal of Reproduction and Fertility 119 35-41

Nelson RJ (1995) An Introduction to Behavioral Endocrinology Sinauer Associates, Inc., Sunderland, Massachusetts

Packard JM, Seal US, Mech LD and Plotka ED (1985) Causes of reproductive failure in two families of wolves (Canis lupus) Zeitschrift fur Tierpsychologie 68 24-40

Richmond M and Stehn R (1976) Olfaction and reproductive behavior in microtine rodents. In Mammalian Olfaction, Reproductive Processes and Behavior pp 197-217 Ed. RL Doty. Academic Press, New York

Riedman ML (1982) The evolution of alloparental care and adoption in mammals and birds Quarterly Review of Biology 57 405-435

Rood JP (1980) Mating relationships and breeding suppression in the dwarf mongoose Animal Behaviour 28 143-150

Savage A, Ziegler TE and Snowdon CT (1988) Sociosexual development, pair bond formation and mechanisms of fertility suppression in female cotton-top tamarins (Saguinus oedipus oedipus) American Journal of Primatology 14 345-359

Schadler MH (1977) Reproductive Patterns and Effects of Population Density on Reproduction in the Pine Mouse, Microtus pinetorum PhD Thesis, Union College, Schenectady, New York

Schadler MH (1990) Social organization and population control in the pine vole, Microtus pinetorum. In Social Systems and Population Cycles in Voles pp 121-130 Eds RH Tamarin, RS Ostfeld, SR Pugh and G Bujalska. Birkhauser, Verlag, Base

Schadler MH and Butterstein GM (1979) Reproduction in the pine vole, Microtus pinetorum. Journal of Mammalogy 60 841-844

Schadler MH and Butterstein GM (1987) Increase in serum levels of luteinizing hormone (LH) in pine voles, Microtus pinetorum, after induction of estrus and copulation Journal of Mammalogy 68 410-413

Schoech SJ, Mumme RL and Moore MC (1991) Reproductive endocrinology and mechanisms of breeding inhibition in cooperatively breeding Florida scrub jays (Aphelocoma C. coerulescens) Condor 93 354-364

Schoech SJ, Mumme RL and Wingfield JC (1996) Delayed breeding in the cooperatively breeding Florida scrub-jay (Aphelocoma coerulescens): inhibition or the absence of stimulation? Behavioral Ecology and Sociobiology 39 77-90

Snowdon CT, Ziegler TE and Widowski TM (1993) Further hormonal suppression of eldest daughter cotton-top tamarins following birth of infants American Journal of Primatology 31 11-21

Solomon NG (1993) Body size and social preferences of male and female prairie voles, Microtus ochrogaster. Animal Behaviour 45 1031-1033

Solomon NG and French JA (1997) Cooperative Breeding in Mammals Cambridge University Press, Cambridge

Solomon NG, Vandenbergh JG, Wekesa KS and Barghusen L (1996) Chemical cues are necessary but insufficient for reproductive activation of female pine voles (Microtus pinetorum) Biology of Reproduction 54 1038-1045 
Solomon NG, Vandenbergh JG and Sullivan WT, Jr (1998) Social influences on intergroup transfer by pine voles (Microtus pinetorum) Canadian Journal of Zoology 76 2131-2136

Stamps JA (1991) Why evolutionary issues are reviving interest in proximate behavioral mechanisms American Zoologist 31 338-348

Wasser SK and Barash DP (1983) Reproductive suppression among female mammals: implications for biomedicine and sexual selection theory Quarterly Review of Biology 58 513-538

Willingstorfer WJ, Burda H and Winckler J (1998) Ovarian growth and folliculogenesis in breeding and nonbreeding females of a social rodent, the Zambian common mole-rat, Cryptomys sp. Journal of Morphology $23733-41$

Received 30 October 2000.

First decision 22 February 2001.

Accepted 13 April 2001. 